\title{
EFFECT OF DIFFERENT HYDROCOLLOIDS ON BARBARI BREAD TEXTURE AND MICROSTRUCTURE
}

\author{
G. MaleKi and J.M. Milani* \\ Department of Food Science and Technology, Sari Agricultural Sciences and Natural Resources University, \\ P.O. Box 578, Sari. Iran
}

(Received: 30 September 2012; accepted: 17 December 2012)

\begin{abstract}
Applying several hydrocolloids in ascending concentrations ( $0.1,0.5$ and $1 \% \mathrm{w} / \mathrm{w}$ flour basis) to bread making procedure was considered. Effect of hydrocolloids [guar, xanthan gum, carboxylmethylcellulose (CMC), and hydroxypropylmethylcellulose (HPMC)] as bread improver on Barbari (Iranian bread) was analysed in terms of microstructure. Image analysis parameters, hardness, and microstructure of fresh bread were analysed. The results confirmed the ability of hydrocolloids for improving fresh bread quality. Among all used hydrocolloids, HPMC and CMC produced the softest texture, smoothest and continuous structure, and improved overall the bread quality.
\end{abstract}

Keywords: Barbari, bread, hydrocolloids, SEM, texture, quality

A large proportion of calorie and protein in people's diet is supplied from wheat. Most of the breads in Asia generally are produced from soft wheat flour, which has higher extraction compared with Western ones. Barbari is a well-known flat bread produced in many parts of the world, such as Iran, Turkey and some Arab countries. It is kind of flat bread made from flour of $78 \%$ extraction. It has a 70-80 cm length, 25-30 cm width, and $1.5-2 \mathrm{~cm}$ thickness in most parts that reaches to $2.5-3 \mathrm{~cm}$ at the two ends (QAROONI, 1996). It is very palatable when freshly baked; however, it loses its quality and stales quickly within a few hours after baking. Therefore, improving the quality and increasing the shelf-life of Barbari bread is of great importance.

Texture and microstructure of bread are factors which significantly influence bread quality, food industries and researches have used some additives to gratify these needs. One of the widely applicable additives in bread processing is hydrocolloids. The hydrocolloids are water soluble polysaccharides with a set of functional properties that make them very influential in food technology (BÁrCENAS \& Rosell, 2005). Different hydrocolloids (derived from herbs, bacteria, seaweeds and also chemical substances) can be used in bakery products.

In recent years many studies have focused on the use of hydrocolloids as bread improvers. Xanthan can increase water absorption and the ability of the dough to retain gas and consequently makes porous texture in final bread (CoLlAR et al., 1999). The effect of sodium alginate, k-carrageenan, xanthan gum and HPMC on bread specific volume, hardness, and moisture content has been evaluated (Rosell et al., 2001). Guar, xanthan, arabic and locust bean gums, carrageenans, alginates, pectins and cellulose derivatives have been used to improve bread quality (Rosell et al., 2001; Sharadanant \& Khan, 2003; Guarda et al., 2004). POLAKI and co-workers (2010) studied the effect of HPMC and locust bean gum on the microstructural and sensory characteristics of fresh and frozen stored bread.

\footnotetext{
* To whom correspondence should be addressed.

E-mail: jmilany@yahoo.com
} 
Therefore, the purpose of this study was to compare the effect of four hydrocolloids (guar, xanthan gum, CMC and HPMC) in three concentrations $(0.1,0.5,1 \% \mathrm{w} / \mathrm{w}$ ) as bread improvers on texture and microstructure of fresh Barbari bread.

\section{Materials and methods}

\subsection{Materials}

The ingredients used in this study were as follows: commercially available refined wheat flour $(12 \%$ water content, $0.74 \%$ d.b. (dry basis) ash content, $11.29 \%$ d.b. protein content obtained from "Khabazi” Mill, Tehran, Iran), fresh compressed yeast, salt, guar gum, xanthan gum, CMC and HPMC (Sigma, Aldrich, Germany).

\subsection{Bread making procedure}

Barbari bread was prepared according to FARIDI and co-workers (1981). In this study for laboratorial tests, samples were prepared in smaller size than the real ones $(24 \times 12 \mathrm{~cm})$. All tests were performed on cooled bread $2 \mathrm{~h}$ after baking.

\subsection{Moisture content}

The moisture of the crumb was determined according to the method used by SHITTU and coworkers (2007). One gram of crumb was placed into a Petri dish, which had previously been weighed. The Petri dish and sample were transferred into the oven set at $105^{\circ} \mathrm{C}$ to dry to a constant weight for $2 \mathrm{~h}$. At the end of the $2 \mathrm{~h}$, the Petri dish and sample were removed from the oven and transferred to desiccators, where they were cooled; the samples were weighed. The amount of moisture content is determined by the difference between the weight of the Petri dish containing the sample before and after being placed in the oven.

\subsection{Crumb hardness}

Crumb hardness was determined according to the A.A.C.C. approved method (1999) using an Instron Universal Testing Machine (Instron Universal Testing Machine/SMT-5, SANTAM Company, Tehran, Iran) at $25^{\circ} \mathrm{C}$.

\subsection{Image analysis of bread crumb}

The crumb of the loaves was assessed using a digital image analysis system. Images of the three central slices (20 mm thickness) from each loaf were captured with a flatbed scanner (Model Scan jet 2410, HP, Cupertino, USA), with a resolution of 600 dots per inch (dpi) converted from true colour to 256 level gray scale. The images were processed using ImagePro Plus 4.5 (Media Cybernetics Inc., USA) software. The crumb grain features determined were: cell total area $\left(\mathrm{mm}^{2}\right)$, mean cell area $\left(\mathrm{mm}^{2}\right)$, mean diameter $(\mathrm{mm})$, min diameter $(\mathrm{mm})$, max diameter $(\mathrm{mm})$ and total cell, cell $\mathrm{cm}^{-2}$.

\subsection{Scanning electron microscopy (SEM)}

For SEM studies, samples were cut in cubes, air-dried, fixed on aluminium stubs with selfadhesive carbon tabs (Agar Scientific Ltd., UK) and sputter-coated with gold. Samples were 
observed and digitally photographed in a XL30 Scanning Electron Microscope (Philips Co., Netherland) at $15 \mathrm{kV}$.

\subsection{Data analysis}

All the results reported are an average of three replicates. Analysis of variance and the Duncan's multiple range test were performed using MSTAT-C version 1.42 software to analyse the data $(\mathrm{P}<0.05)$.

\subsection{Moisture content}

\section{Results and discussion}

The moisture content of bread crumb ranged between $34.34 \%$ and $46.11 \%$ (Fig. 1). Higher moisture content is indicative of a softer bread crumb. The addition of hydrocolloids led to significant increases in crumb moisture content. The best results were obtained by adding $0.5 \%$ hydrocolloid. Despite the reduction of moisture content as the hydrocolloid content was increased to $1 \%$, moisture levels were still higher than without hydrocolloid, which can be attributed to the high water-holding capacity of hydrocolloids.

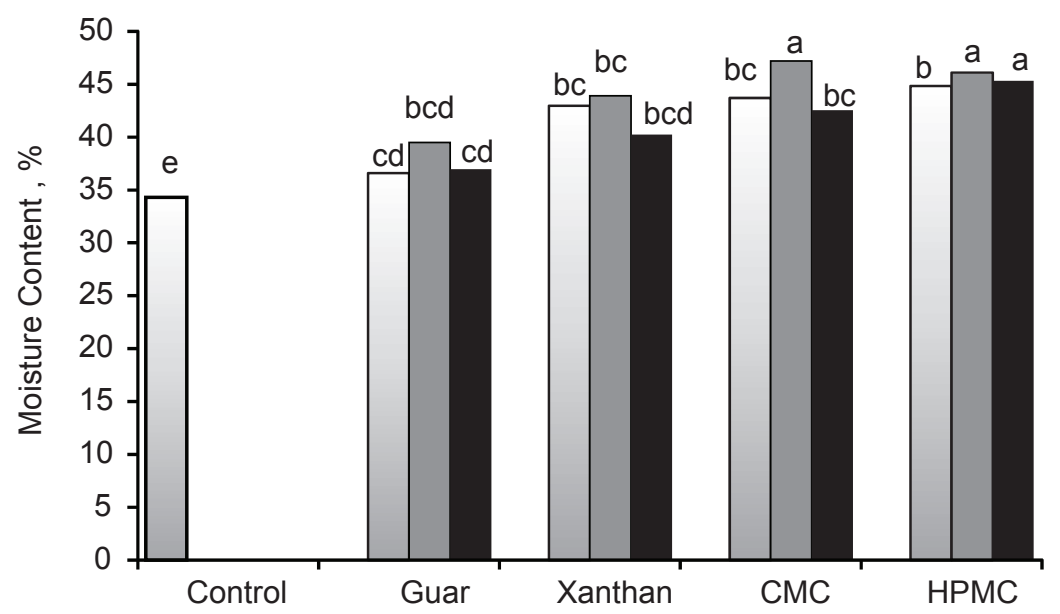

Fig. 1. Crumb moisture of bread containing different concentrations of hydrocolloids. $\square: 0.1 \%$; $\square: 0.5 \%$; $\square: 1 \%$

Hydrocolloids reduce the mobility of the water molecules. Increasing the concentration of hydrocolloids might transform free water to bound water, which is not measureable by this method. The highest moisture was observed in the bread containing $0.5 \% \mathrm{CMC}$ followed by $0.5 \%$ and $1 \%$ HPMC. The moisture content of the bread crumb is determined by factors, such as flour type, used ingredient, and baking condition (GALlAGHER et al., 2004; BÁRCENAS \& Rosell, 2005; Shittu et al., 2007). In this study all factors were constant except for hydrocolloids; therefore, hydrocolloids were the only influential factors. CMC produced bread with higher moisture content, which matches the results of the farinograph. With more hydroxyl groups, cellulose derivatives cause more hydrogen links and have more water holding capacity. The rate and extent of starch re-crystallization are determined primarily by 
the mobility of the crystallisable outer branches of amylopectin. Water plays a very important role because it acts as a plasticizer. A plasticizer is a 'material incorporated in a polymer to increase the polymer's workability, flexibility or extensibility'. Water is unique in that role because of its low molecular weight. It is suggested that granule swelling is restricted by the limited water available in bread dough, and therefore swollen granules retain their identities as discrete particles. The gel produced by diffused amylose from these granules remains less stable during further storage and contributes to the staling process (CAUvaIN \& YounG, 2007).

\subsection{Crumb hardness}

The crumb hardness analysis (Fig. 2) revealed that all hydrocolloids reduced hardness and produced a softer crumb than the control, which is evident in mid-concentration of used hydrocolloids. The effect produced by xanthan in fresh bread was somehow different to the findings of RoselL and co-workers (2001) and GUARDA and co-workers (2004). As xanthan is a natural hydrocolloid, its properties depend on the bacteria species and the extraction process. Hydrocolloids also reduced the hardness of stored bread crumb. This effect was more observable in the mid-concentration of used hydrocolloids, as further addition caused a harder texture. As previously discussed, a higher concentration of hydrocolloids might transform the free water to bound water. Bound water is not able to act as a plasticizer any more. This may cause the hardness in bread containing $1 \%$ hydrocolloids. Hardness in stored bread followed the same trend as crumb hardness in the fresh bread. The use of $0.5 \%$ HPMC in fresh bread led to the softest crumb. Two days after baking, CMC was more effective but HPMC again showed better results for prolonged storage. Stored bread supplemented with xanthan exhibited the greatest increase of hardness. The hardening effect of xanthan might be due to the thickening of the crumb gas cells wall (RoselL et al., 2001).

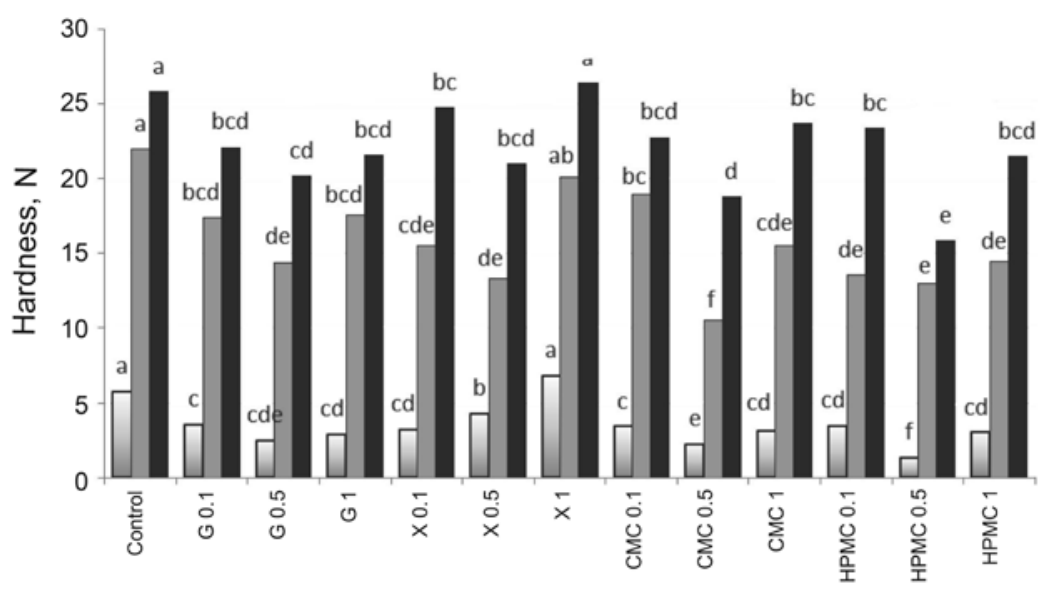

Fig. 2. Crumb hardness of fresh, 3 and 5 day-stored bread containing different hydrocolloids.

$\square$ : day $1 ; \square$ : day $2 ; \square$ : day3 
During storage, the crumb generally becomes harder, dry and crumbly, and the crust becomes soft and leathery. Quite often, these changes are solely attributed to the drying out of the crumb. However, the mechanism of crumb-hardening during storage is far more than simple moisture redistribution from crumb to crust. The overall staling process is mainly one part of two separate sub-processes (GuY et al., 1983): the hardening effect caused by moisture transfer from crumb to crust, and the intrinsic hardening of the cell wall material that is associated with starch re-crystallization during storage.

The softening effect of hydrocolloids should be attributed to their water retention capacity, and a possible inhibition of the amylopectin retrogradation, since they preferentially bind to starch (Collar et al., 2001) and consequently prevent starch-gluten interactions. BILIADERIS and co-workers (1997) also proposed that the effects of hydrocolloids on starch gel structure and mechanical properties result from two opposite phenomena; first, an increase in the rigidity as a consequence of the decrease in the swelling of the starch granules, and second, a weakening effect on the composite starch network structure due to the inhibition of inter-particle contacts among swollen granules. The combination of these factors probably determines the general effect on the mechanical properties of the bread structure, which is dependent on the structure and origin of each used hydrocolloid. With heat, HPMC forms a thermal reversible gel that builds up to a very strong gel at temperatures above $50{ }^{\circ} \mathrm{C}$ but reverts back to a weak entanglement after cooling (GROVER, 1982). This stabilizes the gelatinizing crumb structure during baking temperatures but reduces crumb hardness after baking.

\subsection{Image analysis of bread crumb}

According to Table 1, none of the added concentrations of guar gum and xanthan gum made any significant differences to the control bread in the image analysis parameters, except for total cell, in which case a $1 \%$ addition of them led to a significant increase. All parameters were significantly affected by adding 1\% of HPMC. Both CMC and HPMC in all concentrations were influential in min diameter and cell $\mathrm{cm}^{-2}$. As the strength of the dough containing hydrocolloids decreased, its capacity to sustain large cells was also reduced. Gas cell coalescence was reduced and more gas was lost to the atmosphere. Since the cells were less likely to coalesce, they remained discreet and, smaller with thicker cell walls. Therefore, the number of total cells in bread containing hydrocolloids was higher, but the cell total area was lower than the control bread.

\subsection{SEM analysis}

The micrographs of the bread containing hydrocolloids compared with the control are displayed [only the lowest and the highest concentrations ( 0.1 and 1\%) are shown] in Fig. 3. Control bread had a less dense structure and more pores than the bread containing hydrocolloids as RiBOTTA and co-workers (2004) working with guar gum, BÁRCENAS and Rosell (2005) investigating the influence of HPMC in bread structure, and BÁRCENAS and Rosell (2006) studying the effect of temperature and HPMC addition previously concluded this. The gas cell wall of the control showed a strong connection among all the components, forming a complex structure with numerous cavities (Fig. 3A). This complexity was reduced by adding hydrocolloids until a smoother structure with a smaller number of cavities appeared by adding the highest concentration. Starch granules are clearly shown in the breads containing the smallest concentration (Fig. 3b, c, d and e). Comparing guar, xanthan, CMC 
and HPMC (1\%) revealed that supplementation with HPMC, as ROJAS and co-workers (2000) described, resulted in a continuous structure with thicker appearance and smoother surface (Fig. 3E).

Table 1. Results of image analysis of the crumb porosity of breads containing hydrocolloids in different concentrations

\begin{tabular}{lcccccccc}
\hline & $\begin{array}{c}\text { Dosage } \\
(\%)\end{array}$ & $\begin{array}{c}\text { Cell total } \\
\text { area }\left(\mathrm{mm}^{2}\right)\end{array}$ & $\begin{array}{c}\text { Mean cell } \\
\text { area }\left(\mathrm{mm}^{2}\right)\end{array}$ & $\begin{array}{c}\text { Mean } \\
\text { diameter } \\
(\mathrm{mm})\end{array}$ & $\begin{array}{c}\text { Min } \\
\text { diameter } \\
(\mathrm{mm})\end{array}$ & $\begin{array}{c}\text { Max } \\
\text { diameter } \\
(\mathrm{mm})\end{array}$ & Total cell & Cell/ $/ \mathrm{cm}^{2}$ \\
\hline Control & & $308.3^{\mathrm{c}}$ & $1.875^{\mathrm{c}}$ & $1.267^{\mathrm{cd}}$ & $0.803^{\mathrm{e}}$ & $1.517^{\mathrm{d}}$ & $145.667^{\mathrm{cd}}$ & $54.626^{\mathrm{a}}$ \\
GG & 0.1 & $520.3^{\mathrm{abc}}$ & $2.935^{\mathrm{abc}}$ & $1.166^{\mathrm{d}}$ & $0.799^{\mathrm{e}}$ & $1.775^{\mathrm{bcd}}$ & $120.667^{\mathrm{d}}$ & $43.458^{\mathrm{abc}}$ \\
& 0.5 & $370.5^{\mathrm{bc}}$ & $2.523^{\mathrm{bc}}$ & $1.272^{\mathrm{cd}}$ & $0.853^{\mathrm{de}}$ & $1.708^{\mathrm{bcd}}$ & $151.667^{\mathrm{cd}}$ & $41.848^{\mathrm{abcd}}$ \\
& 1 & $540.9^{\mathrm{ab}}$ & $2.118^{\mathrm{c}}$ & $1.184^{\mathrm{d}}$ & $0.805^{\mathrm{e}}$ & $1.556^{\mathrm{cd}}$ & $253.667^{\mathrm{ab}}$ & $49.379^{\mathrm{ab}}$ \\
$\mathrm{XG}$ & 0.1 & $361.4^{\mathrm{bc}}$ & $2.067^{\mathrm{c}}$ & $1.230^{\mathrm{cd}}$ & $0.836^{\mathrm{de}}$ & $1.664^{\mathrm{cd}}$ & $172.333^{\mathrm{cd}}$ & $48.687^{\mathrm{ab}}$ \\
& 0.5 & $436.9^{\mathrm{abc}}$ & $2.190^{\mathrm{c}}$ & $1.320^{\mathrm{cd}}$ & $0.877^{\mathrm{cde}}$ & $1.740^{\mathrm{bcd}}$ & $199.000^{\mathrm{bc}}$ & $45.683^{\mathrm{ab}}$ \\
& 1 & $384.7^{\mathrm{abc}}$ & $2.400^{\mathrm{bc}}$ & $1.313^{\mathrm{cd}}$ & $0.846^{\mathrm{de}}$ & $1.736^{\mathrm{bcd}}$ & $251.333^{\mathrm{ab}}$ & $44.924^{\mathrm{abc}}$ \\
& 0.1 & $421.6^{\mathrm{abc}}$ & $2.980^{\mathrm{abc}}$ & $1.418^{\mathrm{abc}}$ & $0.966^{\mathrm{abc}}$ & $1.897^{\mathrm{abc}}$ & $146.000^{\mathrm{cd}}$ & $34.145^{\mathrm{bcd}}$ \\
& 0.5 & $485.8^{\mathrm{abc}}$ & $4.016^{\mathrm{a}}$ & $1.589^{\mathrm{a}}$ & $1.036^{\mathrm{a}}$ & $2.178^{\mathrm{a}}$ & $123.667^{\mathrm{d}}$ & $25.291^{\mathrm{d}}$ \\
& 1 & $410.1^{\mathrm{bcd}}$ & $3.141^{\mathrm{abc}}$ & $1.396^{\mathrm{bc}}$ & $0.929^{\mathrm{bcd}}$ & $1.898^{\mathrm{abc}}$ & $131.000^{\mathrm{cd}}$ & $31.981^{\mathrm{bcd}}$ \\
& 0.1 & $509.4^{\mathrm{abc}}$ & $2.775^{\mathrm{abc}}$ & $1.349^{\mathrm{bcd}}$ & $0.924^{\mathrm{bcd}}$ & $1.821^{\mathrm{abcd}}$ & $185.000^{\mathrm{cd}}$ & $36.275^{\mathrm{bcd}}$ \\
& 0.5 & $591.3^{\mathrm{a}}$ & $2.621^{\mathrm{abc}}$ & $1.325^{\mathrm{cd}}$ & $0.916^{\mathrm{bcd}}$ & $1.717^{\mathrm{bcd}}$ & $152.333^{\mathrm{cd}}$ & $39.130^{\mathrm{bcd}}$ \\
& 1 & $579.0^{\mathrm{ab}}$ & $3.792^{\mathrm{ab}}$ & $1.515^{\mathrm{ab}}$ & $0.984^{\mathrm{ab}}$ & $2.060^{\mathrm{ab}}$ & $282.667^{\mathrm{a}}$ & $27.258^{\mathrm{cd}}$ \\
\hline
\end{tabular}

Means $(n=3)$ followed by the same letter in each column are not significantly different $(\mathrm{P}<0.05)$

Although this effect is much more apparent with HPMC, addition of xanthan and CMC also provided a somewhat continuous structure (Fig. 3C and D). It seems that these polymers incorporate other bread constituents and could be intimately linked with the other dough components, and prevent them to interact with one another, which results in better quality and retards staling (BÁrcenas \& Rosell, 2005).

\section{Conclusions}

Use of hydrocolloids in bread-making resulted in improved bread quality, namely moisture content, crumb hardness, porosity and microstructure of the fresh bread compared with that of the control. Cellulose derivatives were more influential. Bread containing CMC and HPMC had higher moisture content. The addition of 1\% HPMC and 1\% CMC produced the softest crumb and smoothest texture. The ability of hydrocolloids to retain moisture and gas resulted in a softer and porous texture. The microstructure analysis suggested the existence of multiple interactions between the polymer and the bread constituents, which could explain the ability of the hydrocolloid to retard the bread staling process. 

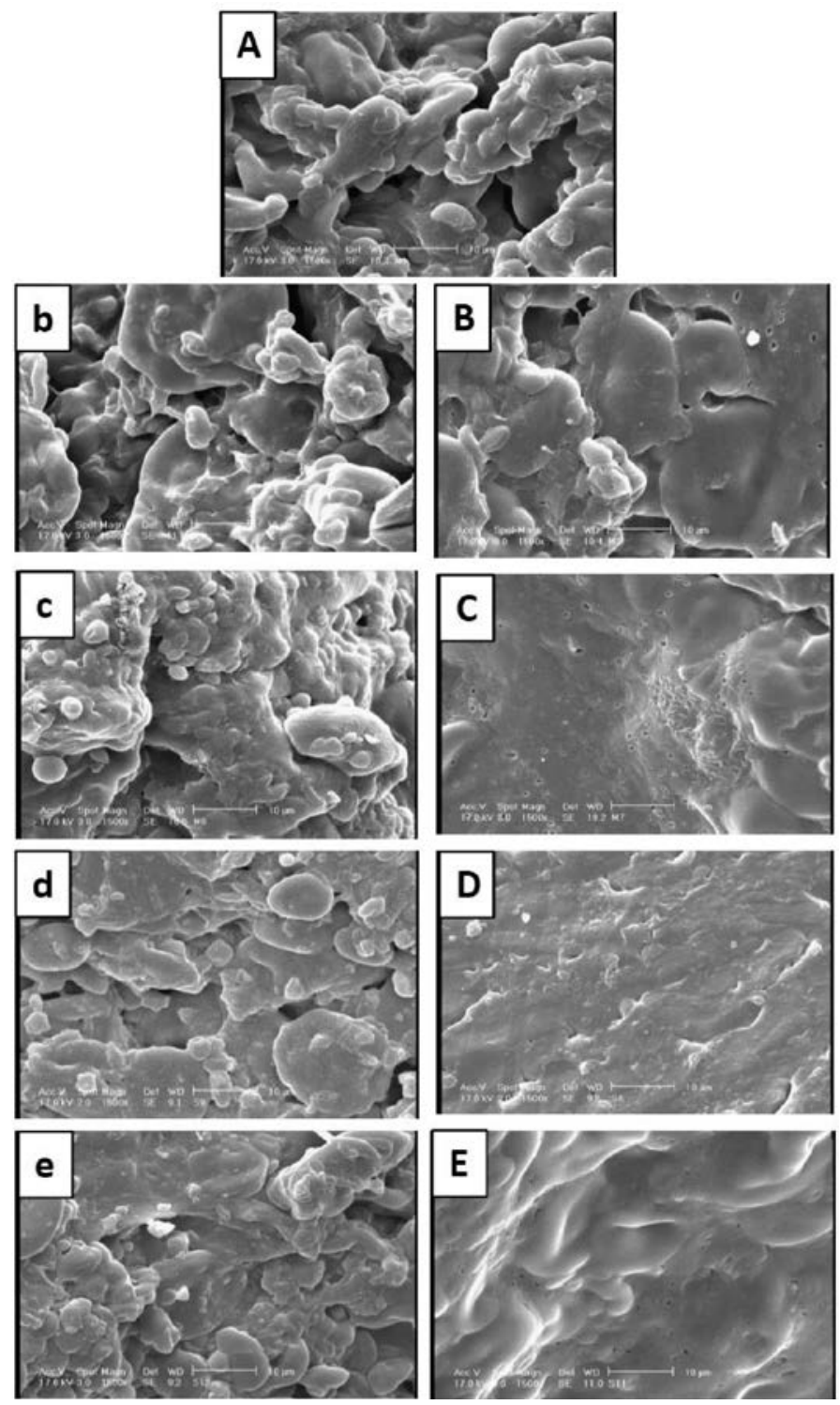

Fig. 3. SEM micrographs showing the effect of different hydrocolloids $(\times 1500)$. A: control; b, B: guar gum; c, C: xanthan gum; d, D: CMC; e, E: HPMC; b, c, d, e: bread containing 0.1\% hydrocolloid; B, C, D, E: bread containing $1 \%$ hydrocolloid

\section{References}

A.A.C.C. (1999): Bread hardness by universal testing machine. Approved method of American Association of Cereal Chemists 74-09, the Association, St. Paul, MN.

BÁrcenas, M.E. \& Rosell, C.M. (2005): Effect of HPMC addition on the microstructure, quality and aging of wheat bread. Fd Hydrocolloids, 19, 1037-1043. 
BÁrcenas, M.E. \& Rosell, C.M. (2006): Different approaches for improving the quality and extending the shelf life of the partially baked bread: low temperatures and HPMC addition. J. Fd Engng, 72, 92-99.

Biliaderis, C.G., Arvanitoyannis, I., Izydroczyk, M.S. \& Prokopowich, D.J. (1997): Effect of hydrocolloids on gelatinization and structure formation in concentrated waxy maize and wheat starch gels. Starch/Stärke, 49, 278-283.

Cauvain, S.P. \& Young, L.S. (2007): Technology of breadmaking ( $2^{\text {nd }}$ ed.). Springer Science+Business Media, LLC., New York, pp. 285-286.

Collar, C., Andreu, P., Martinez, J.C. \& Armero, E. (1999): Optimization of hydrocolloid addition to improve wheat bread dough functionality: a response surface methodology study. Fd Hydrocolloids, 13, 467-475.

Collar, C., Martinez, J.C. \& Rosell, C.M. (2001): Lipid binding of fresh and stored formulated wheat breads. Relationships with dough and bread technological performance. Fd Sci. Technol. Int., 7, 501-510.

Faridi, H.A., Finney, P.L. \& Rubenthaler, G.L. (1981): Micro baking evaluation of some U.S. wheat classes for suitability in Iranian bread. Cereal Chem., 58, 428-432.

Gallagher, E., McCarthy, D., Gormley, R. \& Arendt, E. (2004): Improving the quality of gluten-free products. Final Project Report RMIS No. 4881.

Grover, J.A. (1982): Methylcellulose (MC) and hydroxypropylmethylcellulose (HPMC). -in: GLicksmen, M., Food hydrocolloids. CRC Press, Boca Raton, pp. 121-154.

Guarda, A., Rosell, C.M., Benedito, C. \& Galotto, M.J. (2004): Different hydrocolloids as bread improvers and antistaling agents. Fd Hydrocolloids, 18, 241-247.

Guy, R.C.E., Hodge, D.G. \& RobB, J. (1983): An examination of the phenomena associated with cake staling. FMBRA Report No. 107, November, CCFRA, Chipping Campden, UK.

Polaki, A., Xasapis, P., Fasseas, C., Yanniotis, S. \& Mandala, I. (2010): Fiber and hydrocolloid content affect the microstructural and sensory characteristics of fresh and frozen stored bread. J. Fd Engng, 97, 1-7.

QArooni, J. (1996): Flat bread technology. Chapman \& Hall. Dept BC, 115 fifth Avenue, New York. 206 pages

Ribotta, P.D., Pérez, G.T., León, A.E. \& AÑón, M.C. (2004): Effect of emulsifier and guar gum on micro structural, rheological and baking performance of frozen bread dough. Fd Hydrocolloids, 18, 305-313.

Rojas, J.A., Rosell, C.M., Benedito De Barber, C., Pérez-Munuera, I. \& Lluch, M.A. (2000): The baking process of wheat rolls followed by cryo scanning electron microscopy. Eur. Fd Res. Technol., 212, 57-63.

Rosell, C.M., Rojas, J.A. \& Benedito De Barber, C. (2001): Influence of hydrocolloids on dough rheology and bread quality. Fd Hydrocolloids, 15, 75-81.

Sharadanant, R. \& Khan, K. (2003): Effect of hydrophilic gums on the quality of frozen dough: II. Bread characteristics. Cereal Chem., 80, 773-780.

Shittu, T.A., RaJi, A.O. \& SAnNi, L.O. (2007): Bread from composite cassava-wheat flour: I. Effect of baking time and temperature on some physical properties of bread loaf. Fd Res. Int., 40, 280-290. 